\title{
Polyaniline-Titanium dioxide composite as humidity sensor at room temperature
}

\author{
S. Kotresh ${ }^{1}$, Y.T. Ravikiran ${ }^{1, *}$, H. G. Raj Prakash ${ }^{2}$, S. C. Vijaya Kumari ${ }^{3}$ \\ ${ }^{1}$ Department of PG Studies and Research in Physics, Government Science College, \\ Chitradurga 577501, India \\ ${ }^{2}$ Department of Physics, JNN College of Engineering, Shivamogga 577204, India \\ ${ }^{3}$ Department of Physics, SJM College of Arts, Science and Commerce, Chitradurga 577501, India \\ *ytrcta@gmail.com
}

PACS 81.07.Pr

DOI 10.17586/2220-8054-2016-7-4-732-739

\begin{abstract}
In the present work, Polyaniline (PANI) and Polyaniline-Titanium dioxide (PANI-TiO ${ }_{2}$ ) composite have been synthesized separately by chemical polymerization of aniline without/with $\mathrm{TiO}_{2}$. Characteristic absorption bands of PANI and $\mathrm{TiO}_{2}$ in the composite were confirmed by FT-IR studies, indicating the interaction of PANI with $\mathrm{TiO}_{2}$. Comparative study of XRD patterns of PANI and the composite confirmed superficial deposition of PANI on $\mathrm{TiO}_{2}$ and the average size of the composite particle was found to be $25 \mathrm{~nm}$. The aggregated granular porous morphology of the composite was confirmed by its SEM image. The composite's sensing response to humidity at room temperature was tested and was found to be $84.21 \%$ in the range $25 \%-95 \% \mathrm{RH}$. The response and recovery time of the composite at $95 \% \mathrm{RH}$ were measured to be $60 \mathrm{~s}$ and 100 s respectively and its sensing stability over a period of one month was also confirmed.
\end{abstract}

Keywords: polyaniline composites, humidity sensor, sensitivity, stability.

Received: 9 February 2016

Revised: 26 April 2016

\section{Introduction}

In recent years, nanocomposites have evolved as the most sought after materials in various fields such as sensors, super capacitors, catalysis, light emitting diodes and fuel cells because they offer flexibility in terms of tuning their electrical and mechanical properties for best synergetic effects [1-5]. Thus, reliable fabrication of devices using these materials by cost effective methods is a major concern of many researchers. One such method is the incorporation of metal/metal oxides into the conducting polymers via a chemical or electrochemical route $[6-12]$.

With the advancement of moisture-sensitive technologies and the increasing awareness for quality of life issues, humidity sensing has gained in importance in various areas like medicine, agriculture and electronic industries [13]. With the rapid advances in technology, increasing efficiency, reducing cost, reliability and miniaturization for fabrication of sensors are the major concerns in any research. In recent years, conducting polymer based sensors have become more favorable over metal oxide based sensors in terms of increased sensitivity, simple processing and their room temperature operation [14]. Among all conducting polymers, PANI is the most preferred because of its unique characteristics, such as tunable electrical and chemical properties, easy processing and low costs [15]. Recently, PANI based metal oxide composites have been found to be more advantageous in terms of enhanced humidity sensitivity and such composites have been studied by many researchers. Electrospun PANI composite nanofibers have shown good sensitivity to humidity with a good recovery and response time as reported by Q. Lin et al. [16]. M.T.S. Chani et al. Studied the humidity sensitivity of an orange dye PANI composite film by impedance measurements and have showed a uniform change in impedance for humidity values ranging from $30-$ $90 \%$ RH [17]. Room temperature humidity sensing of PANI-PVA composite has been studied by Y. Li and others, and they showed that the sensitivity of the composite increases with increased impedance from $10-90 \% \mathrm{RH}$ and has both quick response and recovery times [18]. K. C. Sajjan et al. have reported better humidity sensing response for a PANI-Cr $\mathrm{O}_{2} \mathrm{O}_{3}$ composite over the range $20-95 \% \mathrm{RH}$ [19]. S.C. Nagaraju et al. have reported good humidity sensing response for $\mathrm{PANI}-\mathrm{Pr}_{2} \mathrm{O}_{3}$ composites in the range $10-90 \% \mathrm{RH}$ [20]. In this work, we have attempted to fabricate a low cost humidity sensing device made of $\mathrm{PANI}-\mathrm{TiO}_{2}$ composite which can be easily prepared and operable at room temperature. We preferred $\mathrm{TiO}_{2}$ with $\mathrm{PANI}$ for the composite because it is a white n-type transition metal oxide semiconductor with a wide band gap $(3.0-3.2 \mathrm{eV})$ and has a large dielectric constant $(\sim 100)$ [21,22]. This compound's compatible physical properties were considered favorable for use in fiber optics, photovoltaics, gas sensors, biocompatible materials, electrolytic capacitors and dye sensitized solar cells [21]. 
In this work, PANI and PANI-TiO 2 composite were synthesized by a cost effective, simple in situ chemical polymerization method and were structurally characterized using FTIR, XRD and SEM techniques. Based on these studies, humidity sensitivity of the composite's film prepared by spin coating technique was tested and analyzed. Its stability, recovery and response time have also been studied. Both processability and sensing studies were carried out at room temperature.

\section{Experimental}

\subsection{Materials}

Aniline $\left(\mathrm{C}_{6} \mathrm{H}_{5} \mathrm{NH}_{2}\right)(99.5 \%)$, ammonium persulfate $\left[\left(\mathrm{NH}_{4}\right)_{2} \mathrm{~S}_{2} \mathrm{O}_{8}\right](98 \%)$, hydrochloric acid $(\mathrm{HCl})(34.5 \%)$ and titanium dioxide $\left(\mathrm{TiO}_{2}\right)(99.5 \%)$, all of analytical grade reagents were purchased from s.d. Fine Chemicals, Mumbai, India. Aniline monomer was doubly distilled before use.

\subsection{Preparation of PANI-TiO Pomposite $_{2}$ compon}

The method of preparation of pure PANI and the PANI-TiO ${ }_{2}$ composite at room temperature is as follows; firstly, a solution of $6.7 \mathrm{ml}$ of aniline monomer in $60 \mathrm{ml} \mathrm{1M} \mathrm{HCl}$ was prepared. It was added to $180 \mathrm{ml}$ of deionized water in which $0.67 \mathrm{~g}$ of $\mathrm{TiO}_{2}$ powder was previously dispersed. Then adsorption of aniline on $\mathrm{TiO}_{2}$ was facilitated by sonication of the above mixture. Then $7.5 \mathrm{~g}$ of $\left(\mathrm{NH}_{4}\right)_{2} \mathrm{~S}_{2} \mathrm{O}_{8}$ in $60 \mathrm{ml}$ deionized water was added dropwise into the above mixture with continuous stirring for $30 \mathrm{~min}$ and then allowed to polymerize for 8 $10 \mathrm{hrs}$. The reaction product was collected by centrifugation and washed successively with deionized water and acetone until a clear precipitate was obtained which was dried in vacuum until it turned dark green.

\subsection{Characterization of the samples}

The FTIR spectra of pristine PANI, PANI-TiO ${ }_{2}$ composite and $\mathrm{TiO}_{2}$ were recorded using Nicolet 750 FTIR spectrometer in $\mathrm{KBr}$ medium at room temperature. The X-ray diffraction pattern of each sample was obtained by employing Siemens D-5000 powder X-Ray diffractometer with $\mathrm{CuK} \alpha$ source radiation of wavelength $1.54 \times 10^{-10} \mathrm{~m}$. SEM images of PANI and the composite samples were recorded using a Hitachi S-520 scanning electron microscope.

\subsection{Humidity sensing measurements}

The experimental set up used for humidity sensing measurements has been described previously in our literature [23]. A film of the composite was prepared by dissolving the composite powder in m-cresol and then coating it on a glass plate using spin coating unit (Make: Delta Scientific Pvt. Ltd, India, Model: Delta Spin I). Then, interdigitated silver electrodes were printed on it and it was then placed in a specially designed glass chamber well equipped for maintaining required relative humidity. The chamber was tightly closed at the top with a cork. One end of these electrodes were connected to the film by passing through the cork while the other ends were connected to a digital LCR meter (Make: Hioki, Japan, Model: 3532-50) which recorded the impedance changes before and after exposing the sample to humidity at a selected frequency of $100 \mathrm{~Hz}$. The relative humidity in the chamber was varied using saturated salt solutions and monitored using humidity meter (Mextech-DT-615).

\section{Results and discussion}

\subsection{Fourier transform infrared spectroscopy}

FT-IR analysis was used to examine the composite structure after polymerization. The FT-IR spectra of $\mathrm{TiO}_{2}$, PANI and PANI-TiO ${ }_{2}$ composite are shown in Fig. 1.

The FT-IR spectrum of pure $\mathrm{TiO}_{2}$ (Fig. 1(c)) shows strong absorption bands at $648 \mathrm{~cm}^{-1}$ and $419 \mathrm{~cm}^{-1}$ which are the characteristic vibrations of $\mathrm{TiO}_{2}$. These are respectively assigned to the Ti-O-Ti stretching vibration and for Ti-O and Ti-O-Ti combined stretching vibrations and all these results agreed with the published literature [24].

In the FT-IR spectrum of pristine PANI (Fig. 1(b)), the absorption bands at $3419 \mathrm{~cm}^{-1}, 1600 \mathrm{~cm}^{-1}, 1498 \mathrm{~cm}^{-1}$, $1299 \mathrm{~cm}^{-1}, 1147 \mathrm{~cm}^{-1}$ and $880 \mathrm{~cm}^{-1}$ are attributed to the PANI chain. These are respectively assigned to O-H stretching of absorbed water, the $\mathrm{C}=\mathrm{C}$ stretching of quinoid ring, the $\mathrm{C}=\mathrm{C}$ stretching of benzenoid ring, the $\mathrm{C}-\mathrm{N}$ stretching of imine and secondary amine of PANI backbone, the $\mathrm{C}-\mathrm{H}$ stretching in-plane bending vibration and the 1,4 coupling of aromatic ring and all these have agreed well with the pattern published in the literature $[25,26]$.

The FT-IR spectrum of the composite sample (Fig. 1(a)), exhibited characteristic absorption bands at $3425 \mathrm{~cm}^{-1}$, $1630 \mathrm{~cm}^{-1}, 1497 \mathrm{~cm}^{-1}, 1299 \mathrm{~cm}^{-1}, 1136 \mathrm{~cm}^{-1}, 896 \mathrm{~cm}^{-1}, 611 \mathrm{~cm}^{-1}$ and $419 \mathrm{~cm}^{-1}$, which are associated with the characteristic vibrations of both PANI and $\mathrm{TiO}_{2}$ but with a small shift are due to the interaction of oxygen ions of $\mathrm{TiO}_{2}$ and nitrogen atoms of PANI macromolecules present in the composite [27]. 


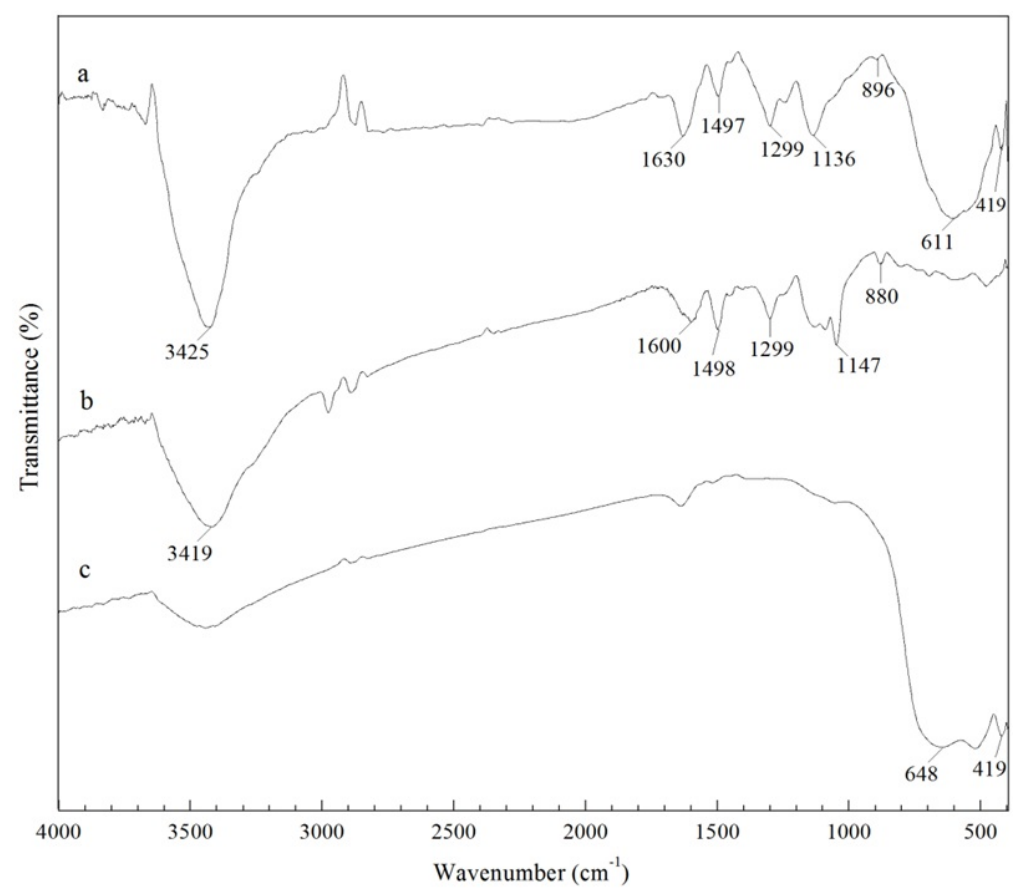

FIG. 1. Fourier transform infrared spectra of (a) $\mathrm{PANI}_{-} \mathrm{TiO}_{2}$ composite (b) Pristine PANI and (c) $\mathrm{TiO}_{2}$

\subsection{X-ray diffraction}

The XRD patterns of PANI, PANI-TiO ${ }_{2}$ composite and that of $\mathrm{TiO}_{2}$ with assigned $h k l$ values are shown in Fig. 2. The XRD pattern of pristine PANI (Fig. 2(a)), reveals some degree of crystallinity with the appearance of broad peaks corresponding to (100) and (110) planes [JCPDS No. 53-1718] in the region $2 \theta=15^{\circ}-25^{\circ}$ similar to those reported in our earlier literature [?,28] The XRD pattern of $\mathrm{TiO}_{2}$ (Fig. 2(c)) clearly shows peaks corresponding to the planes (110) (101) (200) (111) (210) (211) (220) (002) (310) and (112) in the range $2 \theta=$ $20-70^{\circ}$ and the peaks when compared with JCPDS No. 870710 were confirmed to be of rutile $\mathrm{TiO}_{2}$. The same pattern for $\mathrm{TiO}_{2}$ has also been confirmed in previous literatures [29,30].

Comparison of XRD patterns of PANI, $\mathrm{TiO}_{2}$ and the $\mathrm{PANI}^{-\mathrm{TiO}_{2}}$ composite (Fig. 2(b)) indicates predominance of $\mathrm{TiO}_{2}$ in the composite, the rutile phase (110) of $\mathrm{TiO}_{2}$ has remained while the broad weak peaks of PANI have disappeared. All these suggest that there is interaction between PANI and $\mathrm{TiO}_{2}$ and that $\mathrm{TiO}_{2}$ has restricted the growth of PANI chains hampering its crystalline behavior. So it can be concluded that PANI has just deposited on $\mathrm{TiO}_{2}$ and has no effect on the crystalline behavior of $\mathrm{TiO}_{2}$. Similar study has been reported in earlier literature [30].

Applying the Scherrer formula [31] using Eq. (1) to the most prominent sharp peak at $28^{\circ}$, we obtained the size of the crystallite $t$ to be $25 \mathrm{~nm}$ :

$$
t=\frac{k \lambda}{b \cos \theta},
$$

where $b$ is the breadth in radians, $\theta$ is the Bragg angle and $\lambda$ is the wavelength of radiation. The coefficient $k$ normally takes a value close to 0.9 .

\subsection{Scanning electron microscopy}

The morphology of $\mathrm{TiO}_{2}$, PANI and PANI-TiO 2 composite are shown in Fig. 3. The morphology of pristine PANI shown in Fig. 3(a) is an agglomerated granular structure with uniform surface. The morphology of the composite (Fig. 3(b)) shows predominance of $\mathrm{TiO}_{2}$ particles, their surface being covered by PANI, which agrees very well with the results obtained by XRD studies.

The Scanning electron micrograph of $\mathrm{TiO}_{2}$ shown in Fig. 3(c) reveals aggregated granular morphology and agrees well with the SEM images in previously reported studies [32].

The average grain size $D_{A v r}$ of the composite material calculated using Mendelson's formula [33] given by Eq. (2) is $25 \mathrm{~nm}$ :

$$
D_{A v r}=\frac{1.56 \times C_{L}}{M^{\prime} N_{i}}
$$




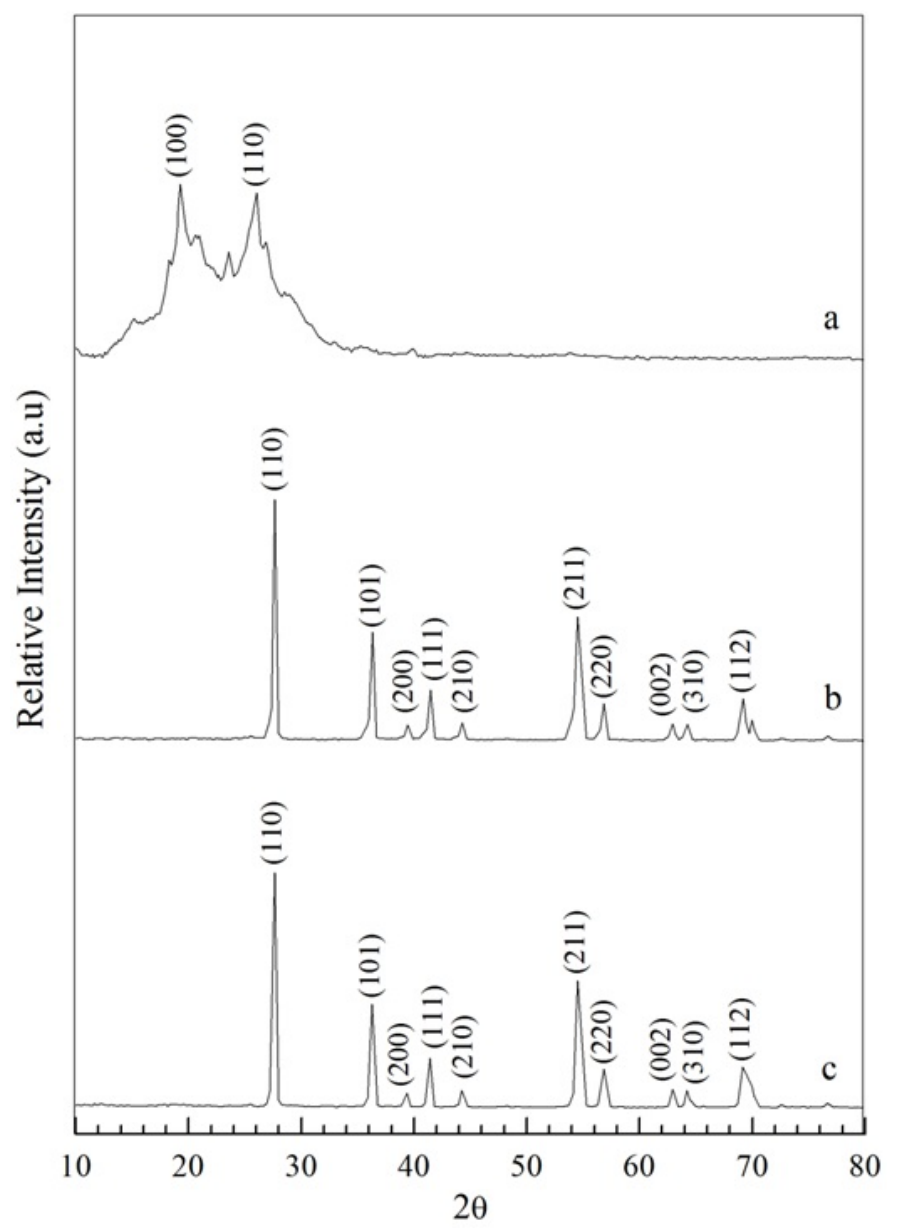

FIG. 2. X-ray diffraction spectra of (a) Pristine PANI (b) $\mathrm{PANI}_{-} \mathrm{TiO}_{2}$ composite and (c) $\mathrm{TiO}_{2}$

where $C_{L}$ is the total length of the test line used, $N_{i}$ is the number of intercepts and $M^{\prime}$ is the magnification of the photograph.

\subsection{Humidity sensing response studies}

The sensing response of the composite for various \% RH are measured at $100 \mathrm{~Hz}$ using fractional base line manipulation method [34] using Eq. (3):

$$
S_{H}=\frac{Z_{0}-Z_{R H}}{Z_{0}} \times 100
$$

where $\mathrm{Z}_{0}$ is the impedance of the sample before exposure to moisture (dry air with $25 \% \mathrm{RH}$ ) and $\mathrm{Z}_{R H}$ is the impedance at various \% RH.

The sensing response characteristic curve of the composite thus obtained by the above method is shown in Fig. 4. It can be seen that the composite is sensitive and its response is linear in the $25-95 \%$ RH range with a maximum sensing response of $84.21 \%$. This linear response of the composite in this range with increasing humidity may be attributed to the following probabilities: (i) At low $\mathrm{RH}$ mobility of $\mathrm{TiO}_{2}$ ions in the composite is restricted due to curling up of polymer chains. As humidity increases, polymer chain uncurls and becomes aligned by absorbing water molecules paving way for faster hopping of charge carriers, resulting in increased sensing response of the composite [21,35]. (ii) Porosity of the polymers as revealed by SEM studies may facilitate absorption of water molecules as RH increases causing a decrease in the impedance of the composite [13].

Efficiency of the composite as a sensing device was studied by measuring its response and recovery times [36]. Humidity sensing response and recovery characteristic curve of the composite at $100 \mathrm{~Hz}$ is shown in Fig. 5. For the purposes of our study, two chambers, one with $25 \% \mathrm{RH}$ and another with $95 \% \mathrm{RH}$ were maintained separately. The response time of $60 \mathrm{~s}$ was recorded when the sample was moved from $25 \% \mathrm{RH}$ to $95 \% \mathrm{RH}$ and a recovery 

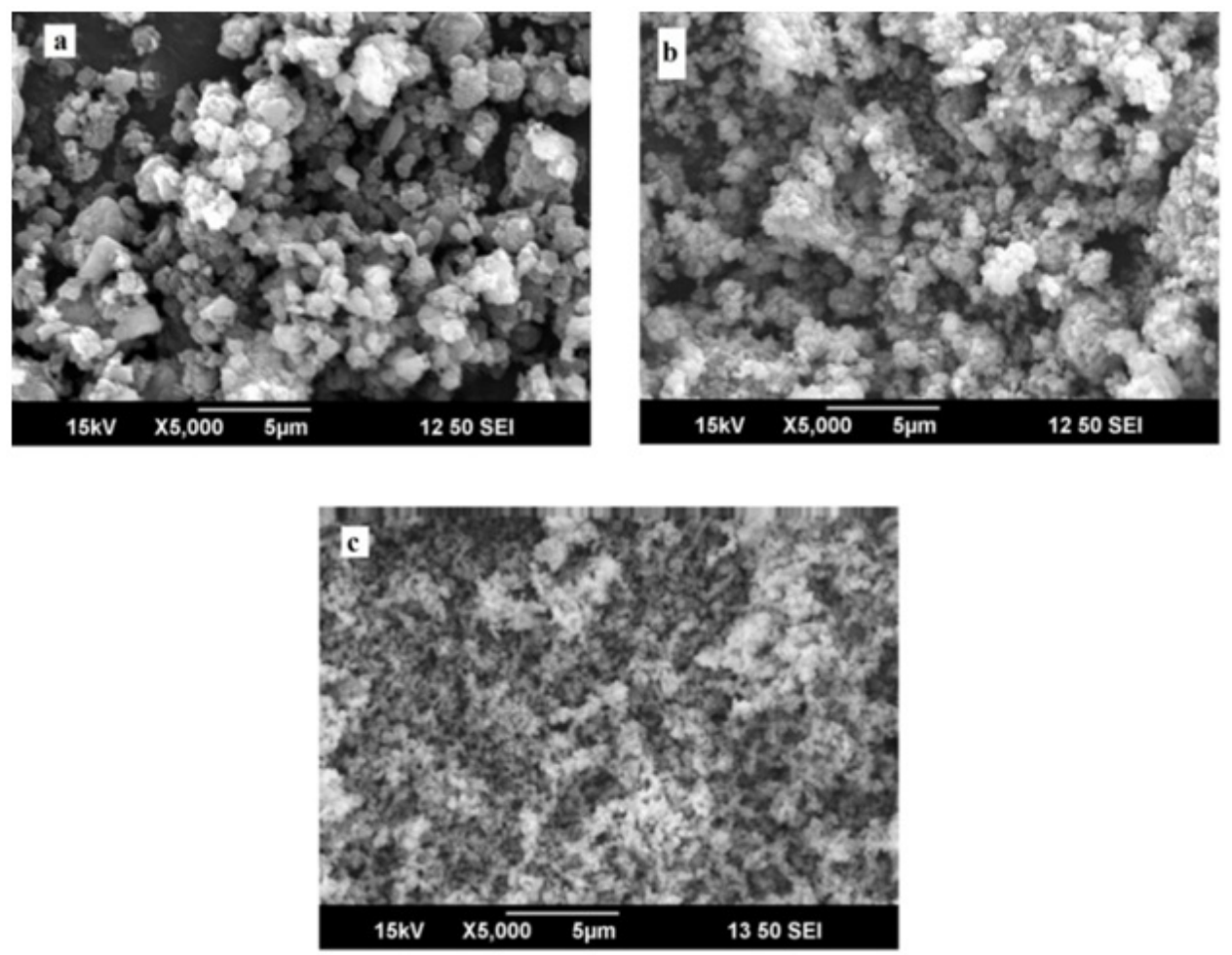

FIG. 3. Scanning electron micrographs of (a) Pristine PANI (b) PANI-TiO 2 composite and (c) $\mathrm{TiO}_{2}$

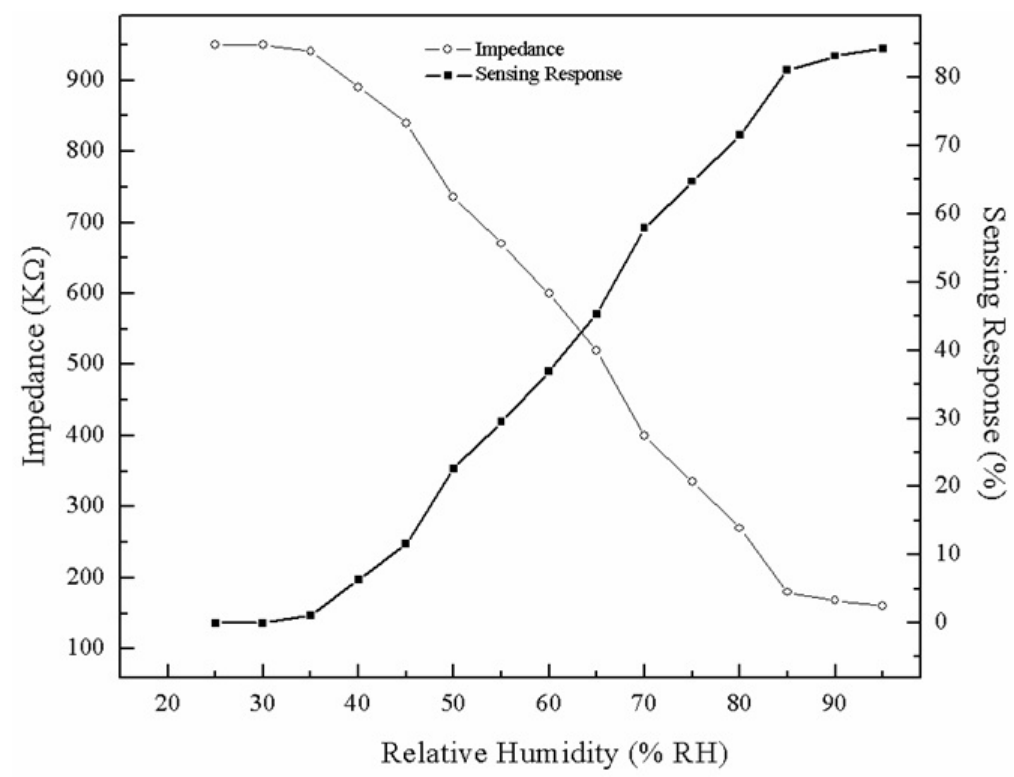

FIG. 4. Variation of sensing response and Impedance with relative humidity at $100 \mathrm{~Hz}$

time of $100 \mathrm{~s}$ was recorded when the sample was moved from $95 \% \mathrm{RH}$ to $25 \% \mathrm{RH}$, switching time being $1 \mathrm{~s}$ in both the cases, establishing that the composite can become a good humidity sensing device.

To examine the practical viability of the composite for use as a sensor, variation of sensing response at $55 \%$ $\mathrm{RH}$ and at $95 \% \mathrm{RH}$ at a frequency of $100 \mathrm{~Hz}$ after every one week for one month was studied [37]. The results presented in the graph shown in Fig. 6 suggest stable sensing ability both during adsorption and desorption with a negligible degradation of $3 \%$ in sensing response. This finding suggests that the composite, apart from being a good sensor, is also stable and so it can be practically feasible to utilize it in a sensor device. 


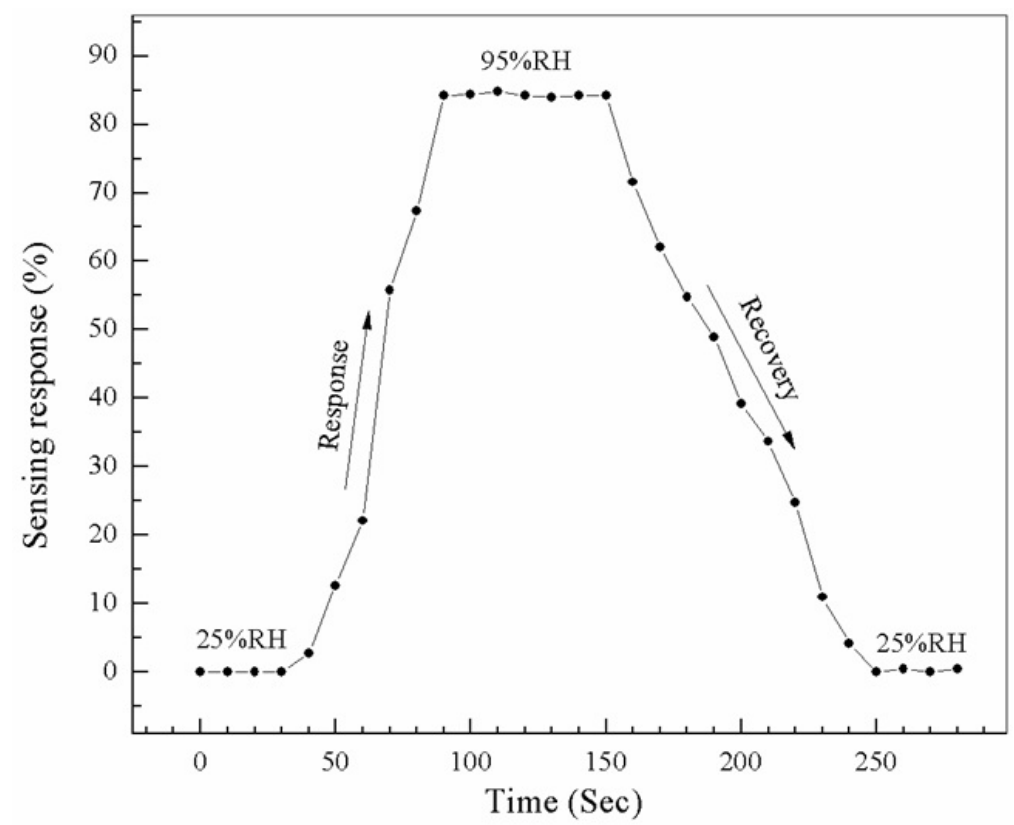

FIG. 5. Response and recovery characteristic curves of PANI- $\mathrm{TiO}_{2}$ composite at $100 \mathrm{~Hz}$

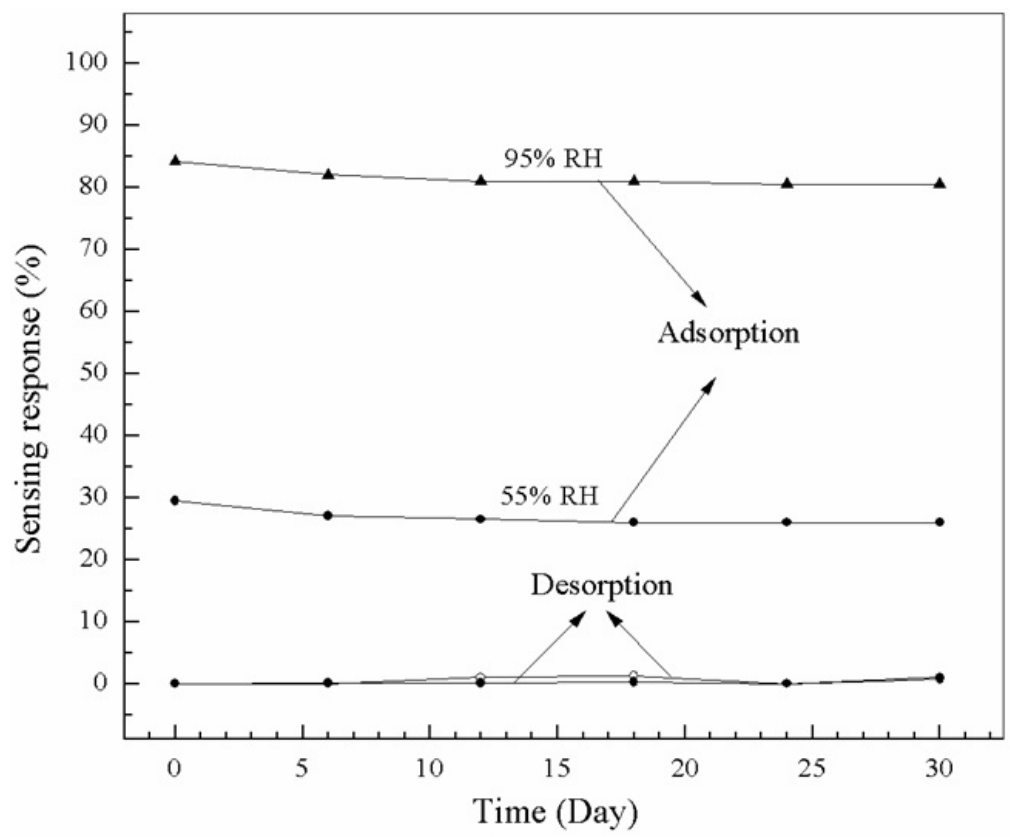

FIG. 6. Stability of PANI-TiO 2 composite at $100 \mathrm{~Hz}$

\section{Conclusions}

The PANI- $\mathrm{TiO}_{2}$ composite synthesized by simple chemical polymerization method showed a room temperature sensing response of $84.21 \%$ in the range $25 \%-95 \% \mathrm{RH}$. The sensing response of the composite film prepared by cost effective spin coating method was measured using LCR meter at a selected frequency of $100 \mathrm{~Hz}$. The efficiency of the composite as a sensor was also confirmed with a recorded response time of 60 s and a recovery time of 100s. The composite has shown stable sensing ability over a period of one month. All these results show that the composite has the potential to become an efficient humidity sensing device operable at room temperature besides being easily prepared and cost effective. 


\section{Acknowledgement}

The author is thankful to the University Grants Commission, New Delhi, for their financial support provided under major research project (41-917/2012 (SR) dated: 23/07/2012), to carry out this work. The Author wishes to acknowledge SAIF, Cochin, for providing facility for characterization of the samples. The author is also thankful to Commissioner, Department of Collegiate Education, Government of Karnataka and Principal Prof. C.M. Vivekananda, Government Science College, Chitradurga for their encouragement and support to carry out this research work.

\section{References}

[1] Tang W., Peng L., Yuan C., Wang J., Mo S., Zhao C., Yu Y., Min Y., Epstein A.J. Facile synthesis of 3D reduced grapheme oxide and its Polyaniline nanocomposites for super capacitor application. Synth. Met., 2015, 202, P. 140-146.

[2] Bahloul A., Nessark B., Briot E., Groult H., Mauger A., Zaghib K., Julien C.M. Polypyrrole-covered $\mathrm{MnO}_{2}$ as electrode material for supercapacitor. J. Power Sources., 2013, 240, P. 267-272.

[3] Rajesh., Ahuja T., Kumar D. Recent progress in the development of nano-structured conducting polymers/nanocomposites for sensor applications. Sens. Actuators B., 2009, 136, P. 275-286.

[4] Memjoglu F., Bayrakceken A., Tuba Oznuluer T., Metin A.K. Synthesis and characterization of polypyrrole/carbon nanocomposite as a catalyst support for fuel cell applications. Int. J. Hydrogen Energy., 2012, 37, P. 16673-16679.

[5] Shin S., Kim S., Kim Y. H., Kim S. Enhanced performance of organic light-emitting diodes by using hybrid anodes composed of polyaniline and conducting polymer. Curr. Appl. Phys., 2013, 13, P. S144-S147.

[6] Ali Y., Vijay K., Sonkawade R.G., Shirsat M.D., Dhaliwal A.S. Two-step electrochemical synthesis of Au nanoparticles decorated Polyaniline nanofiber. Vacuum, 2013, 93, P. 79-83.

[7] Ali Y., Kashma S., Kumar V., Sonkawade R.G., Dhaliwal A.S. Polypyrrole microspheroidals decorated with Ag nanostructure: Synthesis and their characterization. Appl. Surf. Sci., 2013, 280, P. 950-956.

[8] Ali Y., Vijay K., Sonkawade R.G., Dhaliwal A.S. Effect of swift heavy ion beam irradiation on Au-Polyaniline nanocomposite films. Vacuum, 2013, 90, P. 59-64.

[9] Kadam S.B., Datta K., Ghosh P., Kadam A.B., Khirade P.W., Kumar V., Sonkawade R.G., Gambhire A.B., Lande M.K., Shirsat M.D. Improvement of ammonia sensing properties of poly(pyrrole)-poly (n-methylpyrrole) nanocomposite by ion irradiation. Appl. Phys., A 2013, 100, P. 1083-1088.

[10] Ghoreishi K.B.,Yarmo M.A., Nordin N.M., Samsudin M.W. Enhanced catalyst activity of WO 3 using polypyrrole as support for acidic esterification of Glycerol with Acetic Acid. J. Chem., 2013, article ID 264832, P. 1-10.

[11] Lee S.B., Lee S.M., Lee S., Chung D.W. Preparation and characterization of conducting polymer nanocomposite with partially reduced grapheme oxide. Synth. Met., 2015, 201, P. 61-66.

[12] Kanwal F., Siddiqi S.A., Batool A., Imran M., Mushtaq W., Jamil T. Synthesis of polypyrrole-ferric oxide $\left(\mathrm{Ppy}_{-}-\mathrm{Fe}_{2} \mathrm{O}_{3}\right)$ nanocomposites and study of their structural and conducting properties. Synth. Met., 2011, 161, P. 335-339.

[13] Ramaprasad A.T., Rao V. Chitin-polyaniline blend as humidity sensor. Sens. Actuat. B, 2010, 148, P. $117-125$.

[14] Zeng F.W., Liu X., Diamond D., Lau K.T. Humidity sensors based on Polyaniline nanofibres. Sens. Actuat. B, 2010,143 , P. 530-534.

[15] MaDiarmid A.G. Semiconducting and metallic polymers: The fourth generation of polymeric materials. Synth. Met., 2002 , 125, P. 11-22.

[16] Lin Q., Li Y., Yang M. Highly sensitive and ultrafast response surface acoustic wave humidity sensor based on electrospunpolyaniline/poly (vinyl butyral) nanofibres. Anal. Chim. Acta., 2012, 748, P. 73-80.

[17] Chani M.T.S., Karimov K.S., Khalid F.A., Abbas S.Z., Bhatty M.B. Orange dye polyaniline composite based impedance humidity sensors. Chin. Phys., 2012, 22, P. 010701.

[18] Li Y., Deng C., Yang M. Novel surface acoustic wave-impedance humidity sensor based on composite of polyaniline and poly (vinyl alcohol) with a capacity of detecting low humidity. Sens. Actuators, B, 2012, 143, P. 7-12.

[19] Sajjan K.C., Roy A.S., Parveen A., Khasim S. Analysis of DC and AC properties of a humidity sensor based on polyaniline-chromium oxide composites. J Mater Sci: Mater Electron., 2014, 25, P. 1237-1243.

[20] Nagaraju S.C., Aashis S. Roy., Prasanna Kumar J.B., Anilkumar K.R., Ramagopal G. Humidity sensing properties of surface modified Polyaniline metal oxide composites. J. Eng., 2014, 8 pages.

[21] Vlazan P., Ursu D.H., Moisesc C.I., Miron I., Sfirloaga P., Rusu E. Structural and electrical properties of TiO $2 / \mathrm{ZnO}$ core-shell nanoparticles synthesized by hydrothermal method. Mater. Charact., 2015, 101, P. 153-158.

[22] Marinel S., Choi D.H., Heuguet R., Agarval D., Lanagan M. Broadband dielectric characterization of TiO 2 ceramics sintered through microwave and conventional processes. Ceram. Int., 2013, 39, P. 299-306.

[23] Kotresh S., Ravikiran Y.T., Vijayakumari S.C., Raj Prakash H.G., Thomas S. Polyaniline niobiumpentoxide composite as humidity sensor at room temperature. Adv. Mater. Lett., 2015, 6, P. 641-645.

[24] Ba-Abbad M.M., Kadhum A.A.H., Abu B.M., Takriff M.S., Sopian K. Synthesis and catalytic activity of TiO 2 nanoparticles for photochemical oxidation of concentrated chlorophenols under direct solar radiation. Int. J. Electrochem. Sci., 2012, 7, P. 4871-4888.

[25] Quillard S., Louarn G., Lefrant S., MacDiarmid A.G. Vibrational analysis of polyaniline: A comparative study of leucoemeraldine, emeraldine, and pernigraniline bases. Phys. Rev. B: Condens. Matter. 1994, 50, P. 12496-12508.

[26] Wang P.C., Dan Y., Liu L.H. Effect of thermal treatment on conductometric response of hydrogen gas sensors integrated with HCl-doped Polyaniline nanofibers. Mater. Chem. Phys., 2014, 144, P. 155-161.

[27] Nasirian S., Moghaddam H.M. Hydrogen gas sensing based on polyaniline/anatase titania nanocomposite. Int. J. Hydrogen Energ., 2014, 89, P. 630-642.

[28] Ravikiran Y.T., Kotresh S., Vijayakumari S.C., Thomas S. Liquid petroleum gas sensing performance of polyaniline carboxymethyl cellulose composite at room temperature. Curr. Appl. Phys., 2014, 14, P. 960-964. 
[29] Nasirin S., Moghaddam H.M. Effect of different titania phases on the hydrogen gas sensing features of polyaniline/TiO 2 nanocomposite. Polymer, 2014, 55, P. 1866-1874.

[30] Li X., Chen W., Bian C., He J., Xu N., Xue G. Surface modification of $\mathrm{TiO}_{2}$ nanoparticles by polyaniline. Appl. Surf. Sci., 2003, 217, P. 16-22.

[31] Patterson A.L. The scherror formula for x-ray particle size determination. Phys. Rev. B, 1939, 56, P. $978-982$.

[32] Marija B.R., Milica V.M., Dejan S.M., Edin H.S., Gordana N.C.M., Maja M.R., Zoran V.S. Influence of TiO 2 nanoparticles on formation mechanism of $\mathrm{PANI} / \mathrm{TiO}_{2}$ nanocomposite coating on PET fabric and its structural and electrical properties. Surf. Coat. Technol., 2015, 278, P. 38-47.

[33] Mendelson M.I. Average grain size in polycrystalline ceramics. J. Am. Ceram. Soc., 1969, 52, P. $443-446$.

[34] Sen T., Shimpi N.G., Mishra S., Sharma R. Polyaniline $/ \gamma-\mathrm{Fe}_{2} \mathrm{O}_{3}$ nanocomposite for room temperature LPG sensing. Sens. Actuat. B, 2014, 190, P. 120-126.

[35] Lin W.D., Chang H.M., Wu R.J. Applied novel sensing material graphene/Polypyrrole for humidity sensor. Sens. Actuat. B, 2013, 181, P. 326-331.

[36] Qi Q., Zhang T., Wang S., Zheng X. Humidity sensing properties of KCl-doped ZnO nanofibers with super-rapid response and recovery. Sens. Actuat. B, 2009, 137, P. 649-655.

[37] Zhang Y., Zheng X., Zhang T., Gong L., Dai S., Chen Y. Humidity sensing properties of the sensor based on $\mathrm{Bi}_{0.5} \mathrm{~K}_{0.5} \mathrm{TiO}_{3}$ powder. Sens. Actuat. B, 2010, 147, P. 180-184. 